\title{
TONDONGKOERA, EEN BERGDORP IN ZUID-WEST-CELEBES ${ }^{1}$ ).
}

DOOR

Dr. C. NOOTEBOOM.

Een volkenkundige beschrijving van een enkel dorp heeft alleen dan haar volle waarde en haar juisten toon, indien zij wordt gesteld tegen den achtergrond van een cultureele schets van een grootere groep waartoe dit dorp behoort. Een overzicht over het makassaarschboegineesche cultuurgebied ontbreekt echter nog. Zelfs de daartoe noodige voorstudies zijn maar voor een heel klein deel gemaakt. Wel kan men in de zeer uitgebreide literatuur over dit land een groot aantal feiten en feitjes vinden, over een samenvattend onderzoek kunnen we nog niet beschikken. De uitvoering daarvan zou een groote taak zijn die veel tijd en veel geduld zou eischen. Men kan ook niet vooruit weten of een eenigszins afgerond beeld dezer cultuur er mede zal kunnen worden geteekend.

Zelf was ik slechts in staat kennis te maken met enkele kleinere deelen van het gebied, zoodat het opbouwen van zoodanig beeld uit eigen wetenschap mij niet mogelijk is. Ik verzamelde er wel gegevens die ook voor het materiaal over Tondongkoera van beteekenis zijn, doch dit alles bleef fragmentarisch omdat mijn ambtswerk nu eenmaal voor wetenschappelijk onderzoek weinig tijd liet.

In de laatste jaren vóór het begin van den jongsten wereldoorlog werd in het bijzonder door Dr. A. A. Cense en Mr. H. Th. Chabot, veel materiaal verzameld in Zuid-Celebes, maar helaas verscheen nog maar weinig ervan in druk $^{2}$ ). We moeten vreezen dat de wereldbrand,

1) De inhoud van dit artikel is de - deels omgewerkte, deels verkorte tekst van een voordracht, gehouden voor de maandvergadering van het Oostersch Genootschap in Nederland op Vrijdag 18 Mei 1945.

2) O.m. M. v. Chabot: Over de Makassaarsche samenleving en een erfeniskwestie, TBG. LXXX (1942), p. 325. Dit stuk bereikte mij eerst kortgeleden na afsluiting van deze voordracht. 
die ook Makassar niet ongemoeid liet, dit grootendeels zal hebben weggevaagd; in ieder geval werd het werk deze twee onderzoekers er ontijdig afgebroken. De achtergrond van deze mededeelingen over Tondongkoera kan dus niet zóó volledig zijn als gewenscht is. Zoo veel mogelijk zal ik er van geven uit mijn kennis van andere deelen van Zuid-Celebes, aangevuld met enkele feiten uit de literatuur.

Tondongkoera is sinds het meer intensief worden van het Nederlandsche bestuur over deze streken ingedeeld bij de adatgemeenschap Balotji, onderafdeeling Pangkadjene, afdeeling Makassar van de residentie Celebes en Onderhoorigheden ${ }^{3}$ ). Een groot deel van deze residentie, en wel het zuidwestelijke, wordt ingenomen door het makassaarsch-boegineesche cultuurgebied. De makassaarsche taal is beperkt tot een betrekkelijk klein deel ervan in het Zuiden en Zuidwesten met als kern het sultanaat Gowa. Men heeft geconstateerd dat het Boegineesch in de laatste tientallen jaren veld won t.o.v. het Makassaarsch. Zeer duidelijk is dit langs de westkust, waar de eerstgenoemde taal langzaam maar zeker de overhand krijgt en steeds verder naar het Zuiden opdringt. Een aan andere vormen van het Makassaarsch verwant dialect, het zgn. berg-Makassaarsch, wordt in het binnenland gesproken, met name in de bergen van Gowa, Noord en Noordwest van den Piek van Bonthain en van daar uit in een strook bergland in noordelijke richting. Van dit taalgebied is Tondongkoera de meest noordelijke uitlooper, die reeds sterk onder boegineeschen invloed staat. Dit berg-Makassaarsch is ook verwant aan het Saleiereesch, dat in de noordelijke tweederde deelen van het eiland Saleier wordt gesproken. De woordenschat dezer beide talen heeft vele woorden gemeen. Saleiereesche zilversmeden, meestal afkomstig uit de bergen van de adatgemeenschap Bontobangoen, oefenen in vele streken van Zuid-Celebes al zwervend hun beroep uit. Soms blijven zij daarbij jaren achtereen gevestigd in de dorpen der berg-Makassaren, waar zij zich door de verwantschap van hun taal op hun gemak voelen.

Tondongkoera grenst aan de dorpen Birao, Lanne en Bantimoeroeng der adatgemeenschap Balotji, en aan Boera in Tello Limpoe van het landschap Bone. Het bestaat uit een aantal woongehuchten met in totaal ongeveer 750 zielen. Het gewone type der dorpen in deze streken is een bewoonde dorpskern met tuinhuizen op de verder van de kern gelegen velden. In Tongdongkoera is de kern aanwezig

3) D.i. de toestand in 1939. 
in een oude schuilplaats op den berg, die in normale tijden niet bewoond wordt. De geheele bevolking is verspreid over het dorpsgebied, met dien verstande dat de huizen van het volk gegroepeerd zijn rond de woningen der adellijken. Het beantwoordt dus aan den norm $\left.{ }^{4}\right)$.

Het dorpshoofd draagt den titel van karaeng, d.i. vorst. Deze titel wordt elders in het Makassaarsche gebied door lieden van hoogeren rang gevoerd. Dit wijst er op dat deze dorpsgemeenschap in vroeger tijden een grootere zelfstandigheid kende. De samenvoeging met andere dorpen tot de adatgemeenschap Balotji is een maatregel van het Nederlandsche bestuur. Maar die andere dorpen kenden niet den karaengs-titel voor hun hoofden, al waren zij ook zelfstandig. We moeten hier uit besluiten dat Tondongkoera in deze wereld van bergdorpen een vooraanstaande plaats heeft ingenomen, van oudsher.

De eerste karaeng van Tondongkoera, die de plaatselijke overlevering kent, wordt genoemd bij zijn overlijdensnaam MatinroE ri keselangana, de in den Islam ontslapene ${ }^{5}$ ). Dit wijst er op dat hij op later leeftijd tot dezen godsdienst werd bekeerd. Hij is waarschijnlijk de eerste der hoofden, die Mohammedaan was. Ongeveer zeven generaties geleden was hij aan het bestuur; dat wil zeggen: vóór niet veel meer dan 150 jaren. In ieder geval is het belangrijk minder dan de tijdsduur die verliep sinds de invoering van het Mohammedanisme in de kuststreken, die op 350 jaren is te stellen.

Het geloof in de leer van Mohammed is, evenals andere invloeden van buiten, duidelijk in een veel langzamer tempo in deze bergen doorgedrongen en heeft er minder diepe uitwerking gehad dan in andere, minder geïsoleerde streken. Nog tot den laatsten tijd toe zijn vele bewoners der omliggende dorpen alleen in naam Mohammedaan en vaak zelfs dat nog niet eens. Het behoeft ons daarom niet te verwonderen als we er oude cultuurverschijnselen levend aantreffen die elders afsleten en slechts in naam nog bekend zijn.

4) In afwijking van dezen norm zag men in de laatste tientallen jaren in de kustvlakte van Pangkadjene meer en meer permanente huizen op de sawah's komen. Door het toenemen der veiligheid van persoon en goed was dit mogelijk, terwijl de landbouwers uit ervaring weten dat het huisvuil een goede bemesting der natte velden is.

5) Volgens de traditie heette de eerste karaeng van Tondongkoera met zijn overlijdensnaam matinroE ri kaselangana, de in den Islam ontslapene. De tweede heette matinroE ri tapana, de in zijn geloof(?) ontslapene. De derde was matinroE ri pakéréna, de in zijn land ontslapene; hij zou veel hebben gezworven, maar kwam terug in zijn land om er te sterven. De vierde was een buitenstaander, een neef van den karaeng van Labakkang, aan de kust. 
De grenzen van het tot het dorp behoorende grondgebied zijn aan de bevolking nauwkeurig bekend. Tondongkoera is - evenals andere dorpen in dit gebied - duidelijk een territoriale gemeenschap. Bovendien is het, juist als die andere weer, tevens een genealogische gemeenschap. Vestiging van buiten anders dan door inhuwelijking is zeldzaam, zoo zij al voorkomt. En huwelijken met personen buiten de eigen groep komen maar weinig voor. In de genealogieën die ik opnam, zijn van de 215 huwelijken gesloten tusschen niet-adellijken er slechts 29 met personen van buiten het dorp. Bij de 95 adellijke echtparen waren er 32 van deze soort. Er zijn dus twee factoren die samen het behooren tot de dorpsgemeenschap bepalen: inwoning en afstamming. Inwoning alléén geeft niets als men door afstamming of huwelijk geen rechten heeft. Afstamming alléén zonder inwoning geeft slechts een emotioneelen band zonder recht.

We treffen hier een sociale indeeling aan die van veel beteekenis is in Zuid-Celebes : die der standen ${ }^{6}$ ). Friedericy heeft daarover in zijn dissertatie van 1933 allerlei meegedeeld op grond van eigen waarnemingen en van ervaringen van anderen. Het is hier niet de plaats om op de theoretische beschouwingen in te gaan die de schrijver er aan verbindt. Hoofdzaak in zijn gegevens is dat er in Zuid-Celebes eenige standen zijn te onderscheiden, in hoofdzaak hooge adel, lagere adel, vrijen en slaven. De hooge adel bestaat uit de vorsten en hun verwanten, de lagere uit de geslachten van andere hoofden. Maar tusschen die twee groepen en tusschen lagere adel en vrijen in vertoonen zich vele ,tusschenstanden”, die de grenzen doen vervagen, die overgangen vormen van één stand naar den anderen, ontstaan

Deze Tjemang daeng Siadja (matinroE ri Patoendjoena) was gehuwd met een zuster van zijn voorganger, Tjipa daeng Madingi. De vijfde karaeng was Menola daeng Marala (matinroE ri tapoe temba'na, ontslapen in de standvastigheid van zijn koershouden? (schieten?; tapoe temba'na werd mij weergegeven met ,tetap menembak"). Zes en zeven zijn zoons van Tjemang daeng Siadja en Tjipa daeng madingi. Zij heetten (6) Pamana daeng Panranrang alias matinroE ri katinoeloekana (= keradjinan) en (7) Tontowang daeng Manai alias MatinroE ri sikirina (= zikir). De achtste is Parakasi daeng sitaba, door zijn moeder een kleindochter van den vijfden (Menola daeng Marala). Zijn zoon is Pasolong daeng Matepoe, die na een kort bestuur als negende karaeng van Tondongkoera werd benoemd tot karaeng van Balotji. Hij werd opgevolgd door zijn zwager (zuster's man) Saenong daeng Patombong, afkomstig van het dorp Malakka, dien ik in deze functie gekend heb. Dit was dus de tiende karaeng.

$\left.{ }^{6}\right)$ Dr. H. J. Friedericy, De Standen bij de Boegineezen en Makassaren, cpgenomen in dl. 90 van deze bijdragen p. $448-602$. 
door huwelijken tusschen niet-standgenooten. Friedericy's gegevens zijn afkomstig uit Mandar, Wadjo en Goa. Wat men mij in Saleier over dit onderwerp mededeelde sulit zich in hoofdzaak er bij aan ${ }^{7}$ ).

Dit is het beeld der standen in een ruimere sociale omgeving, waar menschen uit vele dorpen met elkaar verkeeren. Het is ook het beeld dat de Makassaar of Boeginees desgewenscht aan U geeft. Door speciaal onderzoek blijkt er echter nog een aspect te bestaan dat door den man van het land zelf niet onmiddellijk onderkend wordt. Chabot constateerde dat de vele grootere en kleinere niveau-verschillen tusschen standen en tusschenstanden niet alleen een gevolg zijn van huwelijksverbintenissen, maar dat zij ook kunnen samenhangen met het grootere of kleinere aanzien van de gemeenschap waarin een adellijk geslacht de hoogste plaats inneemt ${ }^{8}$ ).

Hij teekent ons het sociale beeld van het Makassaarsche dorp als een pyramide, waarvan het grondvlak bestaat uit de groote massa van gewone vrijen en slaven. Daarboven volgen een aantal lagen van lageren adel en tusschen adel, die kleiner worden hoe hooger zij liggen. Daarboven weer is de zeer beperkte groep van de familie van het hoofd en aan den top van het geheel staat dit hoofd zelf als

7) Het hoofd eener adatgemeenschap heet op Salcier Opoe, een titel die ook uit Loewoe bekend is.

Het huwelijk van een Opoe met een anak opoe of patola tinoh geeft den tijdens het ambt van den vader geboren kinderen den titel van anak gaoekang. Is de vader niet zuiver van afstamming dan zijn de kinderen geen ,patola tinol" (echte patola).

De kinderen uit het huwelijk van een opoe, een anak gaoekang of een patola tinoh met een taoe sa'mara (vrije) zijn van den stand der daeng.

De kinderen van een patola tinoh of een anak gaoekang met een standgenoot zijn patola bambang (warme patola).

Opoe anak ganekang en patola tinoh met anak daeng geeft patola, die niet meer tot den rang van opoe kunnen geraken.

Opoc, anak gaockang en patola tinoh met een ata (slavin) geeft anak tjéra (een „rood”- of „bloed”-kind) of anuk séhali (éénzijdig kind).

Patola bambang met anak opoe geeft patola bambang, met taoe sa'mara geeft daeng. Patola met taoe sa'mara geeft eveneens daeng. Taoe sa'mara met een vrouw patola opoc (tinoh) is verboden, met patola geeft taoe sa'mara, met patola bambang geeft patola. Daeng met patola bambang is verboden, met patola daeng.

De volgorde dezer standen en tusschenstanden is: opoe, anak gaoekang, anak opoe, patola tinoh, patola bambang, patola, daeng, taoe sa'mara, anak tjéra, ata.

s) Dit ontleen ik aan een door Mr. H. Th. Chabot gehouden voordracht op het Congres van Taal- en Volkenkundigen te Makassar in Mei 1939, nader aangevuld met persoonlijke mededeelingen. $\mathrm{Zie}$ ook bovengenoemde studie van Chabot in TBG. 1942. 
hoogste vertegenwoordiger der gemeenschap. $\mathrm{Zijn}$ aanzien in de wereld is het aanzien van zijn groep, en omgekeerd.

Een dergelijke sociale structuur treft men overal aan in dorpen met ouderwetsche geslotenheid; zulke dorpen zijn tot op zekere hoogte zelfgenoegzame eenheden, waarin de menschen vrijwel al hun behoeften bevredigd vinden. Ook de huwelijken worden grootendeels binnen het dorp gesloten. We zagen dat ook Tondongkoera maar een klein percentage huwelijken met buitenstaanders kende. Alleen in den hoogsten adelsrang wordt de huwelijkskeus tusschen gelijkwaardige partners in de eigen groep te gering. Men is daarom gedwongen buiten het dorp te zoeken en vormt zoodoende banden met de buitenwereld die bij alle verkeer hun waarde kunnen bewijzen.

Een dorp is bevolkt met wat men kan beschouwen als één groote familie. Niet dat ieder er zijn betrekking tot ieder ander kan aangeven. Dit is onmogelijk door de huwelijksbeletselen tusschen de standen, al zijn deze niet absoluut. Maar allen leiden er hun afkomst, terecht of fictief, af van de eerste voorouders, de stichters van het dorp. De familieband is er niet meer dan een traditioneele, vaak niet-traceerbare verwantschap, zooals we die in andere culturen in de clans aantreffen.

Die oudste voorouders zijn in zekeren zin heilig voor de groep. Met hen hangt het geloof en de vereering samen van heilige voorwerpen, die in Zuid-Celebes groote beteekenis hebben voor het groepsleven. Ik noem deze heilige zaken, in navolging van het spraakgebruik van dit land, met een wat on-eigenlijken term ornamenten of rijkssieraden. In de inheemsche talen heeten zij aradjang, kalompoan of gaoekang.

De dingen waaruit zoo'n ornament is samengesteld, kunnen van den meest uiteenloopenden aard zijn. In de nota's die o.m. Goedhart over vele streken van Zuid-Celebes samenstelde, kan men er zeer gedetailleerde opsommingen van vinden ${ }^{9}$ ). Het ornament is de stoffelijk geworden essentie der gemeenschap. Alle gezag en aanzien, alle heiligheid is er in geconcentreerd. Het behoort dan ook in handen te zijn van dien afstammeling van het hoofdengeslacht die voor de leiding der groep het meest in aanmerking komt. Afstamming, ornament en openbaar gezag behooren in één hand samen te komen. Zij zijn in zekeren zin aan elkaar identiek. Wie van het juiste bloed is èn het ornament bezit heeft ook het gezag.

Ook Tondongkoera heeft zijn ornament: een oude sabel, die naar

9) De meeste dezer nota's zijn opgenomen in adatrechtbundel XXXVI. 
behooren vroeger met heel veel eerbied werd behandeld. Zooals elders in Zuid-Celebes berustte hij op de vliering van het huis van het hoofd, bij den voorgevel. Witte doeken waren er omgewikkeld, zoodat geen profaan oog schade zou ondervinden van zijn gevreesden aanblik. Regelmatig werd er geofferd, niet alleen door de menschen van Tondongkoera, maar ook door lieden uit de kuststreken, die zich nog op eenige wijze verwant wisten met het dorp. Karaeng lohé, groote vorst was de naam van dit heilige wapen. Het aanzien dat Tondongkoera in deze wereld genoot wordt in de vereering van zijn ornament weerspiegeld.

Dit alles is echter geschiedenis geworden. Er worden geen offers meer gebracht, de witte hulsels zijn er niet meer. Terwijl vroeger de aanblik van het bloote wapen voor ieder onbevoegde doodelijk heette te zijn, ligt het nu onbeschermd in een lade van de kleerkast van het dorpshoofd. Op mijn verzoek liet hij het me bereidwillig zien en gaf het zelfs in mijn handen.

Tegenover het Gouvernement van Nederlandsch-Indië is het dorpshoofd de eenige officiëele gezagsdrager in het dorp en eenige vertegenwoordiger der gemeenschapsbelangen naar buiten. Maar in de werkelijkheid van het dorpsleven staat hij niet alleen in zijn taak. Direct naast hem staat een tweede functionaris, die altijd een familielid van hem is: de karaeng Bontopannoe. Volgens de traditie heet deze functionaris zelfs als oudere broeder de meerdere van den karaeng Tondongkoera. Een oud verhaal vertelt hoe het dorpshoofd vroeger, tijdens de hegemonie van Gowa, aan het hof werd ontboden. Men achtte het toen niet raadzaam het eigenlijke hoofd, d.w.z. Karaeng Bontopannoe, de lange reis te laten maken. Daarom vaardigde deze zijn jongeren broeder af, die ten onrechte door den sultan als hoofd der dorpsgemeenschap werd erkend. Sindsdien wordt de jongere broeder als karaeng Tondongkoera in alle aanrakingen met de buitenwereld naar voren geschoven. Samen dragen zij echter het gezag.

Dit paar wordt in zijn bestuur bijgestaan door een uit twee deelen bestaand college van twaalf mannen, die heeten de vier en de acht moeders, anro apa en anro sagang toedjoe. De raad der vier moeders is het belangrijkste deel van het twaalftal. $Z_{i j}$ hebben alle vier een eigen titel. De eerste is de gelarang tondongkoera, de tweede de karaeng of djanang babang, wat poortwachter beteekent. De derde en vierde heeten karaeng GolaE en karaeng Angorang of anro apa GolaE en anro apa Agorang. 
De gelarang is de rechterhand van het dorpshoofd in alle zaken die de uitvoering van het inwendige bestuur betreffen.

De deurwachter, djanang babang, kreeg zijn titel in tijden van oorlog.

Dan trok de gemeenschap zich terug op een kleine vlakte nabij den top van den berg van Tondongkoera. Deze daalt aan drie zijden met steile, onbegaanbare hellingen af naar een bocht in de Tondongkoerarivier. De eenige toegang tot de woonvlakte was een smal pad dat onder den top langs naar de vierde zijde voerde en daar uitkwam op geleidelijk afdalende heuvels. Deze toegangsweg was gemakkelijk te verdedigen. Het was de babang, deur of poort, waaraan de tweede der anro apa zijn naam ontleende. Hij was belast met de bewaking en in het algemeen met alles wat op den oorlog betrekking had. Aanvoerder der gemeenschap in den strijd. Tot dit ambt werden steeds daartoe wegens persoonlijke eigenschappen geschikte leden der hoofdenfamilie gekozen.

Agorang en GolaE zijn woongehuchten, die ieder hun naam aan één der ,vier moeders” gaven.

De anro sagang toedjoe of raad van ,acht moeders" bestaat uit zeven leden met den titel pengépa en één met den titel papisangpoké. Er zijn twee pengépa Tondongkoera, twee pengépa Bontopannoe; twee pengépa Agorang en één pengépa GolaE.

$\mathrm{Bij}$ defungeeren of overlijden van een der raadsleden vult het college zichzelf aan door uit de bloedverwanten van den afgetredene of gestorvene den meest geschikte te kiezen. Is er geen goede candidaat beschikbaar, dan neemt men een buitenstaander, meestal een verwant van de hoofdenfamilie die door lagere afkomst van moederszijde niet meer tot den hoogsten stand wordt gerekend.

We zien dus in den raad ook het standsprincipe weerspiegeld. De hoogste stand bestaat uit de familie van den karaeng. Iets lager slaat men de auro apa aan. Behalve GolaE, van wien dit niet uit de beschikbare genealogieën bleek, hebben zij allen onder hun voorvaderen enkele leden der karaengsfamilie. De anro sagang toedjoe vormen de lagere adel. Overigens kreeg ik niet den indruk dat deze standen voor het sociale leven in Tondongkoera veel beteekenen,

Niet minder belangwekkend dan de samenstelling van dezen dorpsraad is zijn tak in het dorpsleven. Een van zijn meest op den voorgrond tredende functies is zijn rol bij de sawahbewerking. Tegen den tijd dat met het omploegen der natte rijstvelden moet worden begonnen komt het college bijeen om aan de hand van wichelboeken een 
gunstigen dag voor het begin van het werk vast te stellen. Evenals men dit aan de kust gewoon is wordt op dien dag het palili-feest gevierd. Dit is in vele streken van Zuid-Celebes een der hoogtij-dagen voor de geheele gemeenschap en nauw verbonden met het ornament. Vooral in de adatgemeenschappen langs de kust van Pangkadjene zijn dit groote gebeurtenissen, die met volksfeesten gepaard gaan en met een uitvoerig ceremonieel, waarin de oorsprong der gemeenschap, van het ornament en van de natte rijstteelt samen worden herdacht. In het bijzonder in Segeri zijn deze feesten zeer bekend geworden door de schilderachtige ritueele dansen der bisoe, de kwasi-hermaphrodriten, die in de samenleving als erkende homo-sexueelen (wandoe) een eigen plaats hebben.

Vroeger werd in Tondongkoera het veld palarikang ritueel geploegd in tegenwoordigheid der geheele bevolking. Het was daarbij een goed voorteeken als het span ploegbuffels tijdens de ceremonie op hol sloeg. Gebeurde dit dan had men de zekerheid van een goeden oogst ${ }^{\mathbf{1 0}}$ ). In de plaats van het veld palarikang is tegenwoordig de ambtssawah van den karaeng Bontopannoe gekomen, en buiten den dorpsraad wonen nog slechts weinige menschen de ceremonie bij. Dobbelarijen en hanegevechten zijn verboden. Maar nog steeds is dit ploegen een ritueel, waarvoor men een uitgezocht stel buffels heeft, één mannelijk en één vrouwelijk dier, die bijzondere kenteekenen hebben en ieder jaar opnieuw voor dit doel worden gebruikt. Drie dagen na het ritueele ploegen wordt dezelfde sawah nog eens, maar nu goed geploegd, en wel door den pengépa Bontopannoe, één der acht moeders. Daarna mogen allen met de sawahbewerking beginnen.

Ook voor het begin van elk der volgende fazen van den sawahbouw bepaalt de raad later een geschikten dag. Het uitzaaien, het overplanten van de jonge rijst, en ten slotte de oogst, mogen niet beginnen dan nadat de twaalf moeders van het dorp er hun sanctie aan hebben gegeven en het werk op de ambtssawah van Bontopannoe is begonnen.

In de adatgemeenschappen aan de kust van Pangkadjene is het uitzoeken van goede dagen voor het begin der werkzaamheden op de sawah's een taak van de plaatselijke overheid. De gezamenlijke dorpshoofden met de lieden die de restanten van het officiëele, voor Islamritueel verzorgen, dat zijn de pinati, vergaderen daartoe met den karaeng. Verder gaat echter het parallelisme met Tondongkoera niet.

10) Idem in enkele adatgemeenschappen aan de kust van Pangkadjene.

D1. 104. 
Meestal is de officiëele bemoeienis met den sawahbouw hiertoe beperkt. In Tondongkoera heeft de raad daarentegen veel grootere bevoegdheden. Gedurende de heele periode van de rijstteelt heeft het college een algemeen toezicht op ieders werk. Is er iemand nalatig, dan wijst één der ,moeders” hem op zijn plichten. Verbetert hij zich niet, dan wordt hij voor den karaeng geroepen om een berisping in ontvangst te nemen. Maar zóó ver laat men het zelden komen. Is iemand door ziekte, afwezigheid of anderszins niet in staat zijn werk op de sawah naar behooren te verrichten, dan zorgen de anro dat hij hulp krijgt. Heeft hij geen buffels om zijn ploeg te trekken, dan wordt hem een span geleend. Heeft hij geen zaaipadi, dan wordt hem deze verstrekt. Kan hij niet werken, dan werken anderen voor hem, daartoe geroepen door den raad. De betaling voor de gepresteerde hulp kan later volgen in natura bij den oogst of in werkkracht tijdens den veldarbeid.

Dit toezicht vindt plaats bij alle onderdeelen van het werk. Het begint bij het ploegen, dan bij het maken en verbeteren der sawahdijkjes; het uitzaaien; het uitplanten; het maken van afrasteringen tegen varkens, buffels en herten; het onderhouden der waterleidingen; het bewaken van den aanplant tegen wilde dieren; het wieden der velden. Dit laatste is in deze bergen zeer noodig, daar het opschietende onkruid de muizen uit de omliggende woeste gronden aantrekt. Worden de varkens bij een der sawahcomplexen te lastig, dan organiseert de raad een drijfjacht. De natte rijstbouw wordt in Tondongkoera dus wel heel sterk als gemeenschapsbelang gevoeld en gewaardeerd.

Ook op ander gebied heeft het college bemoeienis. Bij feestelijkheden ter gelegenheid van huwelijk en besnijdenis, evenals bij sterfgevallen moet de raad zorg dragen dat alles naar den eisch verloopt. Bij de feesten moet voldoende rijst, brandhout en een buffel voorradig zijn. Komt men tekort, dan verleent de raad zijn bemiddeling voor het verwerven van het ontbrekende. Bij overlijden van een lid van de karaengs-familie verrichten de anro apa alles wat er noodig is. Sterft iemand van lageren stand, dan treden de anro sagang toedjoe in functie. Het besnijden van de jongens is de taak van den karaeng Agorang. Voor zoover de meisjes een dergelijke behandeling ondergaan komen zij daartoe in handen van zijn echtgenoote.

Voorts moet het college worden geraadpleegd als iemand een huis wil bouwen. Men wendt zich dan eerst tot den karaeng met het verzoek om toestemming voor den aankap van het noodige hout en 
vergunning voor den bouw. Het hoofd roept den raad van twaalf samen om met hem het ingediende verzoek te bespreken. Als er geen bezwaren bestaan kan men ook rekenen dat het werk glad en zonder moeilijkheden zal verloopen, daar de raadsleden het toezicht hebben en zorgen voor voldoende werkkrachten voor den houtaankap en den bouw. Is de raad tegen de ingediende plannen, dan zal niemand trachten zijn wil toch door te zetten, daar hij geen vergunning voor den aankap krijgt en niemand hem zal komen helpen.

Wil men in het jachtseizoen een jachtpartij organiseeren, dan wordt alles wat er noodig is weer door den raad geregeld, zoodat er voldoende drijvers en honden in het terrein komen. Meent de karaeng dat het tijd wordt voor een groote vischvangst in de diepe kolken der rivier, dan komt het college ook in actie. Het is een groote gebeurtenis, die lang wordt voorbereid. Honderden menschen uit andere dorpen komen dan als gasten naar Tondongkoera om een deel van de buit machtig te worden. De stroom wordt tijdelijk afgedamd en met toeba-wortel vergiftigd.

We vinden de bemoeienis van den raad op alle levensgebied der gemeenschap. Dit is alles zonder twijfel oude adat. Toch is het niet waarschijnlijk dat de vorm en de functies van het college der acht en vier moeders gedurende eeuwen als onveranderd cultuurbezit hebben standgehouden. Wat zijn taak betreft valt het op dat de raad, in tegenstelling met andere dergelijke lichamen in Zuid-Celebes, geen rechtspraak schijnt uit te oefenen. Hoewel het voorkomen van misdrijven er - gezien de groote solidariteit in deze gemeenschap wel vrij zeldzaam zal zijn geweest, kan van het ontbreken van misdadigheid geen sprake zijn. Zonder twijfel viel dit onderdeel van de overheidszorg vroeger ook binnen 's raads competentie. We moeten het verdwijnen ervan toeschrijven aan het overnemen van de rechtspraak door van Gouvernementswege angewezen instanties ${ }^{11}$ ). We mogen zelfs verwachten dat een dieper gaand onderzoek nog restanten van zulk een werkzaamheid zou kunnen blootleggen, die mij als ambtenaar voorzichtigheidshalve werden verzwegen.

In ieder geval is hier een beperking in de taak van het college aan te wijzen die plaats greep in de laatste halve eeuw. Een uitbreiding er van, eveneens tengevolge van de toename der bestuursbemoeienis,

11) De heer H. T. Damsté deed mị mededeelingen over de werking van de toenmalige rechtregeling-Der Kinderen, die tijdens zijn bestuur over de onderafdeeling Tjamba (1906) een chaos op het gebied der rechtspraak bleek teweeg te brengen. 
vinden we op ander gebied. Het onderhoud der verbindingswegen tusschen de kampongs, waaraan vroeger geenerlei aandacht werd besteed, is door toezicht van het europeesch bestuur een meer drukkende plicht geworden. Zelfs is Tondongkoera met de buitenwereld verbonden door een, ten minste in den Oost-moesson voor auto's bereidbaren, weg. Het in orde houden van dit ten deele in den bergwand uitgekapte autospoor is aan de hand van de van gouvernementswege gegeven voorschriften omtrent den heerendienst geregeld. Bij de verdeeling van dezen arbeid over de werkplichtige dorpsgenooten en het toezicht op het werk werd de raad op gelukkige wijze ingeschakeld. Het totaal der werkers is over zes groepen verdeeld. Iedere groep staat onder twee van de twaalf dorpsmoeders, die zorgen voor het oproepen en het toezicht. Men zou kunnen verwachten dat iedere groep bestaat uit menschen die zoo dicht mogelijk bij elkaar in de buurt wonen, zoodat het oproepen niet veel tijd kost. Dit zou echter tengevolge hebben dat telkens een heele buurtschap ontbloot zou worden van werkbare mannen, wat bezwaarlijk is voor den landbouw, in het bijzonder voor de bewaking der velden tegen wild en tegen losloopend vee. Dit is de reden dat elk der groepen bestaat uit zooveel mogelijk verspreid wonende mannen.

Het verrichten van heerendiensten in den huidigen georganiseerden vorm is zonder twijfel een nieuwe instelling. Het kan dus niet anders of de bemoeienis van den raad er mede is eveneens iets nieuws, maar op voortreffelijke wijze aangepast bij de functies die het college al vervulde.

Dit zijn enkele wijzigingen in de functies van den raad. Ik wees er ook op dat de samenstelling van dit college wellicht niet constant is geweest. Dit dient nog even nader te worden bekeken. In de Makassaarsche en Boegineesche landen vindt men gewoonlijk in de omgeving van het hoofd der gemeenschap, hij moge een vorst zijn of iemand van lager rang, een kleine groep erfelijke functionarissen, die belast zijn met de zorg voor de attributen der vorstelijke waardigheid. $\mathrm{Zij}$ moeten bij plechtige gelegenheden deze heilige voorwerpen meedragen en in het algemeen is het ritueel met en voor deze zaken aan hen opgedragen. Men vindt er lansen onder, een waterketeltje, een sirih-stel en andere dergelijke voorwerpen. Meestal is er ook een ritueel hakmes bij en eenige voorwerpen van bamboe waarmee een rammelend geluid wordt voortgebracht. Dit alles wordt nauw verbonden gedacht aan het ornament en heeft een eigen ritueele waarde. 
De bedoelde functionarissen hadden in dit ritueele complex ieder een eigen plaats.

Ook in de dorpen Bantimoeroeng en Malakka, in de naaste omgeving van Tondongkoera gelegen, kwamen dergelijke functionarissen nog in vrij recenten tijd voor. In Bantimoeroeng trof ik eenige sawah's aan, die naar hen waren genoemd en als ambtsveld bestemd waren voor hun onderhoud. Men had er de sawah voor den drager van de waterketel, voor den vaandrig, voor den drager van de keuken en van den mondvoorraad. Men had er ook het rijstveld voor den lansdrager, den papisangpoké. We herkennen hierin den titel van één der acht moeders van Tondongkoera, den eenigen die géén pengépa heet.

Dergelijke adatfunctionarissen trof ik niet in Tondongkoera aan. Het ritueel rond het ornament bleek er geheel te zijn afgesleten, zoodat deze ambten er zonder functie zouden zijn. Maar daar ze algemeen in Zuid-Celebes voorkwamen en veelal nog voorkomen, moeten we aannemen dat Tondongkoera er vroeger ook gekend heeft. Ook de titel papisang poké voor één der ,acht moeders” wijst daar op. Het is er mede een aanwijzing voor dat de oude ritueele functionarissen rond het ornament in later dagen opgingen in den dorpsraad of in een deel daarvan. De vaste eigen functies van ieder dezer lieden in het dorpsceremonieel makte plaats voor een meer algemeene met anderen gedeelde taak.

Elders in Zuid-Celebes zijn deze vormen veel meer levend. Bijvoorbeeld op Saleier, in het bijzonder in de adatgemeenschap Tanette, die de noordelijke punt van dit eiland inneemt. Deze menschen zijn er nog altijd vrijgesteld van het verrichten van alle soorten verplichte diensten. $\mathrm{Zij}$ moeten inplaats daarvan bij voorkomende gelegenheden klaar staan om hun taak in het gevolg van het hoofd te volbrengen. Zij zijn de erfelijke vertegenwoordigers van het volk bij het gemeenschapsheiligdom.

We vinden hier een sociale structuur die nauw verwant is aan de organisatie van primitieve gemeenschappen met clanorganisatie. Daar is de samenleving verdeeld in scherp begrensde sectoren gekenmerkt door unilaterale verwantschap. Ieder daarvan heeft eigen wèl omschreven functies op alle onderdeelen van het stamleven. Hier, in Zuid-Celebes, zijn de afstammingslijnen volgens welke de functies in de samenleving vererven minder scherp getrokken. Zij zijn niet unilateraal maar bilateraal; zij kunnen zoowel vader- als moederzijdig zijn met voorkeur voor het eerste. In overeenstemming daarmede is 
er geen duidelijke, goed waar te nemen indeeling der samenleving. Maar de functies zijn gescheiden en erfelijk en beheerschen het maatschappelijk leven zooals de functies der clans dit doen in andere culturen.

Dáár is de leiding der samenleving in handen der clanhoofden, hier in Tondongkoera en ook elders in Zuid-Celebes vinden we een college bestaande uit de hoofden van de voornaamste families, die alle onderling verwant zijn, al is het dan niet met de strenge regelmaat die clansystemen soms laten zien.

Wij hebben iets gezien van den bouw van deze dorpsgemeenschap; we zagen de zorgen der locale overheid voor het economisch leven; het gemeenschapsritueel bleek tot geringe rudimenten afgesleten. Het is in overeenstemming daarmee dat ook de heilige verhalen van het dorp verdwenen. Het was nog maar weinig wat ik er als levende wijsheid te hooren kreeg, toen ik in gezelschap van een groep notabelen de schuilplaats op den bergtop bezocht. Het is het verhaal van de herkomst van een onkwetsbaarheidsmedicijn, die er werd gevonden en die het dorp tot ver buiten zijn grenzen beroemd maakte. Inderdaad weet nog heden het volk van Makassar de beteekenis en de waarde van die tambara Tondongkoera. Het is weinig, dat verhaal van ouden roem en vervlogen grootheid, die het dorpshoofd een eereplaats gaven aan het hof van den sultan van Gowa. Maar nog is het een noodzakelijk deel in de bijzondere positie die Tondongkoera in deze wereld blijkt in te nemen.

Ik ben mij bewust dat mijn schets van het cultureele leven van het dorp Tondongkoera alleen in groote lijnen werd geteekend en dat allerlei lacunes zijn gebleven. Zoo kwam niet ter sprake de plaats die de Islam en zijn voorgangers in het dorpsleven innemen en zijn mijn geslachtslijsten niet volledig genoeg om de sociale structuur geheel te begrijpen. Toch hoop ik er in te zijn geslaagd een beeld te geven van dit kleine, in zekeren zin zelfgenoegzame stukje Makassaarsch leven. Ik teekende het, voor zoover dit mij mogelijk was, in verband met de cultuur van Zuidwest-Celebes, waarvan het een typische vertegenwoordiger is en waarvan het bepaalde aspecten scherper laat zien dan andere groepen in dit cultuurgebied. 